\title{
COMPARISON BETWEEN GERMINATING PARAMETERS OF BASILS (OCIMUM BASILICUM L.) AND PUMPKIN (CUCURBITA PEPO L.) UNDER DROUGHT STRESS CONDITIONS.
}

\author{
FAiza ASHRAF ${ }^{1}$, TAHOORA BATOOL ZARGAR ${ }^{1}$, SZILVIA Veres ${ }^{1,2}$ \\ ${ }^{1}$ University of Debrecen, Faculty of Agriculture, Food Science and Environmental \\ Management, Institute of Crop Sciences, Debrecen, Hungary \\ *Corresponding author: szveres@agr.unideb.hu
}

\begin{abstract}
Drought stress is becoming an intimidating obstacle to global agriculture in the $21^{\text {st }}$ century, creating major food security challenges. Drought-sensitive crops, in particular, to which pumpkin and basils belong, reduce yield potentials. Lack of water can inhibit germination of sown seeds and manipulate germination parameters. An experiment was conducted to investigate the effect of drought stress, induced by (polyethylene glycol) (PEG), on some germination parameters (germination percentage, germination energy, germination rate index, mean germination time and root elongation) of pumpkin (Cucurbita pepo L.) and basil (Ocimum basilicum L.). The PEG concentration in both species was $(2.5 \%)$ along with a control treatment (nutrient solution), on both species in three replicates of every treatment. Germinated seeds were counted every day at the same time, and the daily associated root elongation was measured by using a regular ruler. Each stage was considered finished when the average hypocotyl of the control treatment reached $3 \mathrm{~cm}$ long. Pumpkin took nearly 7 days to reach maximum root elongation, whereas basils took 8 days but failed to reach around $1.5 \mathrm{~cm}$ root length and died. The results showed that basil seeds were extremely sensitive to water deprivation and could not germinate in 2.5\% PEG solution, whereas pumpkin seeds germinated well in $2.5 \%$ PEG solution. It was found that the PEG treatment reduced germination by $25 \%$ in the case of pumpkin, whereas basils could not germinate well and the PEG treatment reduced germination by $75 \%$. It demonstrates that pumpkins can withstand drought stress better than basils.
\end{abstract}

Keywords: Drought stress; germination; polyethylene glycol; pumpkin; basils.

\section{INTRODUCTION}

Climate change will inevitably show its consequences all over the globe as a result of global warming. Temperature rises and shifting weather patterns are likely to exacerbate already-existing water shortages in certain areas. The incidence and intensity of droughts and floods is estimated to adjust, which can lead to a severe death and property loss across Europe (ÖZDEN ET AL., 2008).

Drought is one of the most serious environmental stresses, limiting crop yields in many parts of the world, especially in hot and dry regions. (PORUDAD AND BEG, 2003). Precipitation and water scarcity are the first thoughts that come to mind when drought is discussed. (KULAÇ ET AL., 2010). Drought, which is deteriorating by the day, and thirst as a result of it, have devastating consequences in green fields, as well as in other aspects of our lives. Roots are the first organ in plants to detect drought stress (DAVIES ET AL., 2002; WILKINSON AND DAVIES, 2002), and as a result, plants can form fine roots that can invade smaller soil pores and increase water absorption to some degree (OH AND KOMATSU, 2015; KomATSU AND Hossain, 2013). 
Various methods are used to identify species' drought resistances. One of these methods is to apply polyethylene glycol PEG to the seed's nutrient solution in various concentrations. PEG applications have been used in many species to identify drought resistance, with very positive results (BAHRAMI ET AL., 2012; MUJTABA ET AL., 2007).

Pumpkin seeds are used for the curing of various illnesses, and the herbal drugs are used for medicinal care individually or combined. The pumpkin is the famous food plant used to cure various food illnesses and phytochemical compounds (YADAV ET AL., 2010). Despite these facts, it is considered as drought tolerant crop (SEYMEN ET AL., 2019).

Sweet basil is known as a crucial fresh vegetable and a different medicinal herb. Basil plants include antibacterial, antioxidant, antimicrobial, anti-inflammatory and several other positive consequences for consumer health based on previous study findings (TANRIKULU ET AL., 2018; JULIANI ET AL., 2002). The aim of this experiment was to investigate the effects of artificial of (in laboratory drought stress caused by PEG on germination parameters of Pumpkin and Basil. In this research, the water stress resistance of pumpkin and basil was also identified.

\section{MATERIALS AND METHODS}

The experiment was performed at the Debrecen University Institute of Crop Sciences in 2021. Two distinct species were used to compare germination parameters: Pumpkin ('Curcubita pepo L') (120 seeds) and Basil ('Oscimum basilicum L') (120 seeds).

Pumpkin and basil seeds were hand-selected based on standardized seeds size that were surface sterilized with $6 \%$ (v/v) $\mathrm{H}_{2} \mathrm{O}_{2}$ for 20 minutes, then rinsed four times with distilled water and germinated geotropically between moisten filter papers at $22^{\circ} \mathrm{C}$. The control medium was the nutrient solution (NS) medium (with the addition of the required amount of sterile distilled water). The nutrient solution consisted of the following components:2.0 $\mathrm{mM} \mathrm{Ca}\left(\mathrm{NO}_{3}\right)_{2} \cdot 4 \mathrm{H}_{2} \mathrm{O}, 0.7 \mathrm{mM} \mathrm{K}_{2} \mathrm{SO}_{4}, 0.5 \mathrm{mM} \mathrm{MgSO}_{4} \cdot 7 \mathrm{H}_{2} \mathrm{O}, 0.1 \mathrm{mM} \mathrm{KH} \mathrm{KO}_{4}, 0.1 \mathrm{mM}$

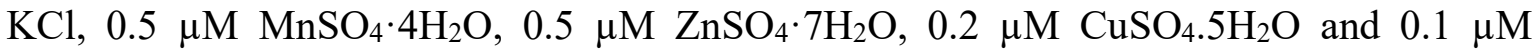
$\mathrm{H}_{3} \mathrm{BO}_{3}$. Iron was provided in the form of $104 \mathrm{M}$ Fe-EDTA. Polyethylene glycol (6000 PEG) (VWR International bvba Geldenaaksebaan, Leuven, Belgium) was used at a concentration of $2.5 \%$ to induce water stress. In case of pumpkin, 20 disinfected seeds were placed on each roll for each treatment, and experiments were carried out in triplicate while 20 sterilized seeds on each roll in case of basils in 3 replications. Seed germination was monitored for 7 days and the parameters of germination were assessed accordingly. Seeds were considered germinated when the radicle had protruded $2 \mathrm{~mm}$ across the coat of the seed. Each stage was declared complete when the average hypocotyl of the control treatment reached $3 \mathrm{~cm}$ in length.

Six different germination parameters were assessed. The methodology of calculations of parameters 1, 2, 3 and 4 followed (AL-MUDARIS, 1998), parameter 5 followed (AOSA, 1983), parameter 6 followed (CZABATOR, 1962). 
1. Final germination percentage $(G)=$ the total seeds germinated at end of trial/number of initial seeds used 100 times.

2. Mean germination time $(\mathrm{MGT})=\Sigma \mathrm{Fx} / \Sigma \mathrm{F}$; where $\mathrm{F}$ is the number of seeds germinated on day $\mathrm{x}$.

3. Germination index $(\mathrm{GI})=\mathrm{G} 1 / 1+\mathrm{G} 2 / 2+\ldots .+\mathrm{Gi} / \mathrm{i}$; where $\mathrm{G} 1$ is the germination percentage on day $1, \mathrm{G} 2$ is the germination percentage at day 2; and so on.

4. Coefficient of velocity of germination $(\mathrm{CVG})=\mathrm{N} 1+\mathrm{N} 2+\ldots+\mathrm{Ni} / 100 \mathrm{x}$ $\mathrm{N} 1 \mathrm{~T} 1+\ldots+\mathrm{NiTi}$; where $\mathrm{N}$ is the number of seeds germinated every day and $\mathrm{T}$ is the number of days from seeding corresponding to $\mathrm{N}$.

5. Seed Vigor Index $(\mathrm{SVI})=[($ mean root length + mean shoot length $) \times$ \%germination]

6. Speed of germination $(\mathrm{GS})=\sum(\mathrm{ni} / \mathrm{ti})$

At the end of the study, the effect of PEG application on the germination percentage, mean germination time, coefficient of velocity of germination, germination index, speed of germination and seed vigor index were analyzed using the Sigma plot program. For statistical analysis Sigma Plot 14 for Windows (Systat Software) was used. During the data analysis, one-way ANOVA method was used.

\section{RESULTS}

The results of the mean value, \pm standard error are given in Table 1. There was a statistically significant difference between control (NS) and polyethylene glycol (PEG)with regards to all germination parameters studied (Table 1). Based on the results of germination parameters, we found a significant difference between the pumpkin and basils was recorded (Table 1). Drought stress affected the root length of basil seeds more than pumpkin seeds, according to the results of the germination parameters. Drought-stressed pumpkin seeds had higher values for the number of roots and root length as compared to basils. In case of pumpkin, GP of control (NS) was (91.6 \pm 1.666 ,) but only (83.3 \pm 1.666$)$ under drought stress conditions. Comparing between pumpkin and basil values of GP were $(63.3 \pm 1.66)$ and $(50 \pm 2.88)$ in control and PEG treatment respectively. Basils were $(13 \%)$ under drought stress. The study's analysis indicated the impact of drought stress on basil germination characteristics. The MGT of basil was significantly greater than that of pumpkins. It indicates that pumpkin seeds could germinate faster than basils. MGT of pumpkin seeds was reduced by $12.6 \%$ compared to basils under PEG (Figure 1.b).

The lowest germination index (GI) was obtained in the stressed group in the case of pumpkin and basil rather than the control group, even when the values between pumpkin and basils are compared (Table 1). The GI value of basil was significantly lower by $20 \%$ in the control. Under PEG conditions, the value of basil was significantly reduced by $40.6 \%$. This shows that the $2.5 \%$ concentration of PEG had no influence on the germination properties of pumpkin, but had a deleterious impact on basils. 
There was a significant difference in the co-efficient of germination velocity between pumpkin and basil when they were subjected to water stress. When treated with PEG, the average coefficient of germination velocity for pumpkin was $(22.658 \pm 0.445)$ and for basil was (19.656 1.111$)$. It was clearly found that pumpkin had a substantially greater SVI value than basils. In pumpkin, the difference between the two treatments was $27.7 \%$. Basils, on the other hand, had (75.7\%) difference. Pumpkins had a substantially higher germination speed (GS) than basils; under non-stressed conditions, GS was (2.714 \pm 0.0824$)$ and $(1.761 \pm 0.047)$ for pumpkin and basils, respectively. Under stressful conditions, the value of pumpkin and basils was (2.333 \pm 0.047$)$ and $(1.4761 \pm 0.095)$, respectively.

Table 1. Values of the germination parameters (Germination percentage GP\%, mean germination time MGT; day, germination Index GI; day, co-efficient of germination velocity $\mathrm{CVG}$; seeds day ${ }^{-1}$, seed vigor index SVI; day, and germination speed GS; day)of Pumpkin (Cucurbita pepo L) and Basil (Ocimum basilicum L) under control (NS) and PEG (drought stress), $(\mathrm{n}=3, \pm$ s.e.)

\begin{tabular}{|c|c|c|c|c|c|c|c|}
\hline & & $\mathrm{G} \%$ & MGT(day) & GI (day) & $\begin{array}{l}\text { CVG(seeds } \\
\left.\text { day }^{-1}\right)\end{array}$ & SVI (day) & GS(day) \\
\hline \multirow{2}{*}{$\begin{array}{l}n \\
\bar{x} \\
\infty \\
\infty\end{array}$} & CONTROL & $63.3 \pm 1.66$ & $4.30 \pm 0.16$ & $4.32 \pm 0.15$ & $23.62 \pm 0.546$ & $206.6 \pm 7.85$ & $1.76 \pm 0.047$ \\
\hline & PEG & $50 \pm 2.88$ & $5.05 \pm 0.33$ & $2.43 \pm 0.41$ & $19.65 \pm 1.111$ & $50.6 \pm 3.614$ & $1.48 \pm 0.095$ \\
\hline \multirow{2}{*}{ 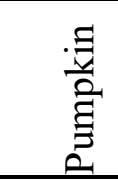 } & CONTROL & $91.6 \pm 1.666$ & $3.49 \pm 0.179$ & $5.51 \pm 0.12$ & $28.78 \pm 1.445$ & $414.0 \pm 2.76$ & $2.71 \pm 0.082$ \\
\hline & PEG & $83.3 \pm 1.66$ & $4.41 \pm 0.085$ & $4.18 \pm 0.242$ & $22.6 \pm 0.445$ & $299.3 \pm 5.04$ & $2.33 \pm 0.05$ \\
\hline
\end{tabular}



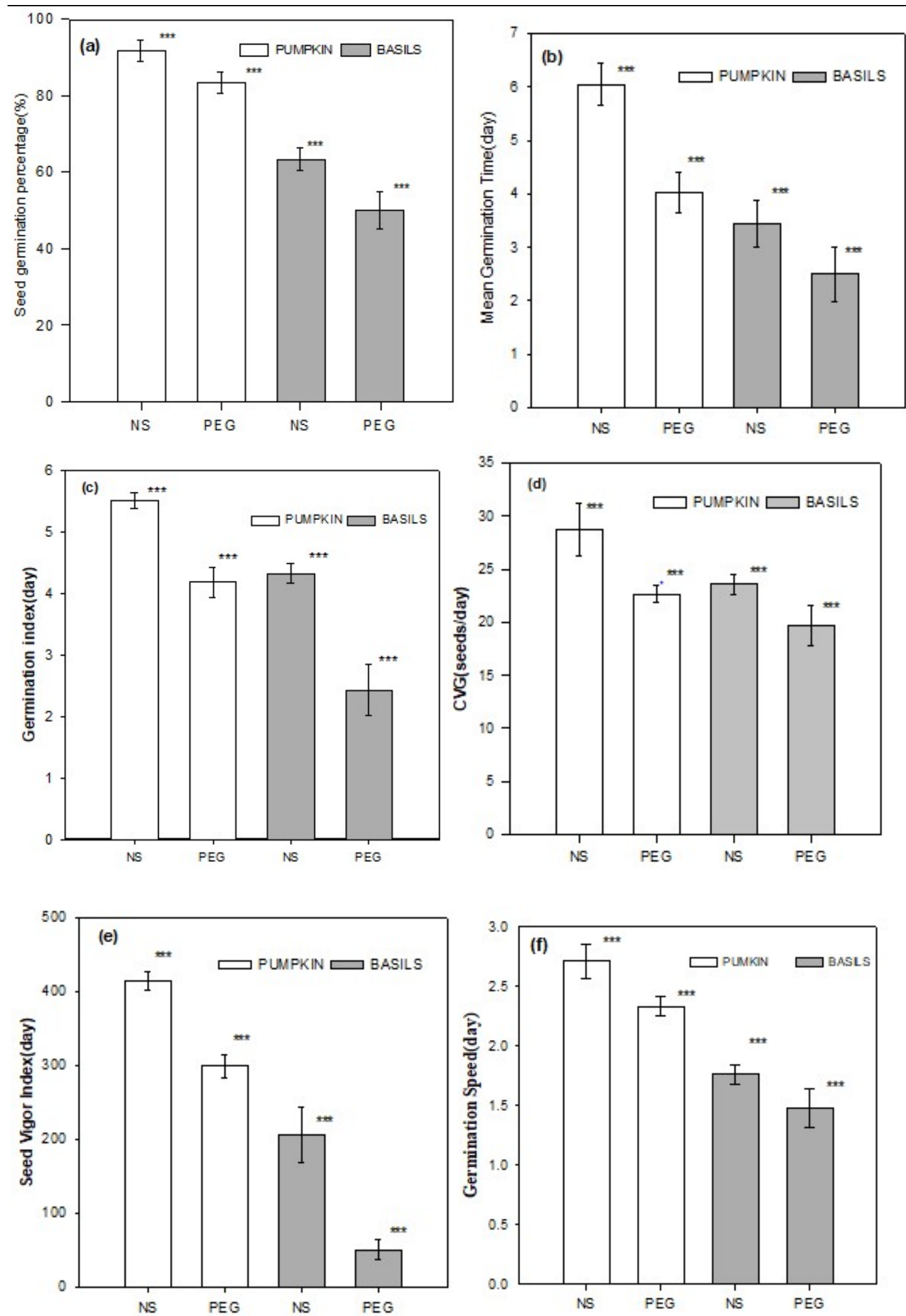

Figure.1 Germination parameters of pumpkin and basil under control (no-drought) and 2.5\% PEG (drought stress) condition: (a) Germination percentage, (b) Mean Germination Time, (c) Germination index, (d) Coefficient of velocity of germination, (e) Seed vigor index, (f) Germination speed, $(n=3, \pm$ s.e. $)$, Significant differences were $\operatorname{signed}^{* * *}(\mathrm{p} \leq 0.001)$. 


\section{DISCUSSION}

Drought stress has been the subject of several research. Despite the fact that pumpkins can withstand drought (MUSA SEYMEN ET AL., 2019). All of the germination parameters for pumpkin and basil have been determined. Because PEG had a higher influence on basil root length and morphological and physiological characteristics, it was determined that basils are drought sensitive. It has been demonstrated by (ALI REZA ET AL., 2014). We discovered a substantial difference in the germination percentage of basils and pumpkins in this study. The pumpkin and basil germination rate was $83.3 \%$ and $50.3 \%$ respectively under PEG condition. Water deprivation has been found to affect all basil germination parameters more than pumpkin. The germination parameters of basils have been considerably affected by the water shortage. Compared with basil, we found no change in the pumpkin germination parameters.

\section{CONCLUSION}

In conclusion, while pumpkin seeds germination percentage was higher under relative drought stress conditions. Germinated Basil seeds showed zero 'tolerance; the roots were unable to go deeper in order to meet more potential water levels. The root length had a notable impact on germination parameters, and it would most likely affect the plant's future growth, which will be very important to examine in order to understand the potential consequences of drought stress on the physiological traits during the later vegetative and reproductive periods of the Basils

\section{ACKNOWLEDGEMENT}

Project no. TKP2020-IKA-04 has been implemented with the support provided from the National Research, Development and Innovation Fund of Hungary, financed under the 2020-4.1.1-TKP2020 funding scheme.

\section{REFERENCES}

Al-Mudaris, M. (1998): Notes on various parameters recording the speed of seed germination. Der Tropenlandwirt, 99:147-54.

AOSA. (1983): Seed vigor hand testing book. Association of Official Seed Analysis, (Contribution No. 32 to the handbook on seed testing.) Springfield, IL

Bahrami, H., Razmjoo, J., Ostadi, J.A. (2012): Effect of drought stress on germination and seedling growth of sesame cultivars (Sesamum indicum L.). International Journal of Agricultural Sciences, 2: 423-428.

Czabator, F.J. (1962): Germination Value an Index Combining Speed and Completeness of Pine Seed Germination. Forest Science, 8: 386-396.

Davies, W.J., Wilkinson, S., Loveys, B. (2002): Stomatal control by chemical signalling and the exploitation of this mechanism to increase water use efficiency in agriculture. New Phytologist, 153 (3):449-60. doi: 10.1046/ j.0028-646X.2001.00345. x. 
Juliani, H., Simon, J.E., Ramboatiana, M.R., Behra, O., Garvey, A., Raskin, L. (2002): Malagasy aromatic plants: essential oils, antioxidant and antimicrobial activities. XXVI International Horticultural Congress: The Future for Appl Res Med Aromat Plants, 629: 77-81.

Komatsu, S., Hossain, Z. (2013): Organ-specific proteome analysis for identification of abiotic stress response mechanism in crop. Frontiers in Plant Science, 4:71. doi:10.3389/fpls.2013.00071.

Kulaç S. (2010): Drought stress exposed Scots pine (Pinus sylvestris L.) seedlings in some morphological and physiological Investigation of biochemical changes. Ph.D. Thesis, Karadeniz Technical University, Institute of Science and Technology. Trabzon. (in Turkish).

Mujtaba, S.M., Ali, M., Ashraf, M.Y., Khanzada, B., Farhan, S.M., Shirazi, M.U., Khan, M.A., Shereen, A., Mumtaz, S. (2007): Physiological responses of wheat (Triticum aestivum L.) genotypes under water stress conditions at seedling stage. Pakistan Journal of Botany, 39(7): 2575-2579

Oh, M., Komatsu, S. (2015): Characterization of proteins in soybean roots under flooding and drought stresses. Journal of Proteomics, 114:161-81. doi: 10.1016/j.jprot.2014.11.008.

Özden, S., Tetik, C., Yavaş, O.M., H.G., Çiftçi, A. (2008): Europe needs to be done to work on climate change adaptation and disaster reduction of damage due to climate change in Turkey. 5th World Water Forum regional preparatory process DSi domestic regional water meetings snow hydrology conference proceedings, Erzurum pp. 95-103. (in Turkish).

Porudad, S.S., Beg, A. (2003): Safflower: Asuitable oil seed for dryland areas of Iran. In: proceeding of $7^{\text {th }}$ international conference on development of drylands. Sep. 14-17. Tehran, Iran.

Tanrıkulu, G.İ., Ertürk, Ö., Yavuz, C., Can, Z., Çakır, H.E. (2018): Chemical compositions, antioxidant and antimicrobial activities of the essential oil and extracts of Lamiaceae family (Ocimum basilicum and Thymbra spicata) from Turkey. International Journal of Stress Management, 4: 340-348.

Yadav, M., Jain, S., Tomar, R., Prasad, G.B.K.S., Yadav, H. (2010): Medicinal and biological potential of pumpkin. Nutrition Research Review, 23(2): 184- 190. 